\title{
DEMOCRATIZAÇÃO E ENSINO: EM BUSCA DA DIMINUIÇÃO DAS DESIGUALDADES SOCIAIS
}

\author{
${ }^{1}$ Gildoberg Nunes da Silva, Universidade Federal de Campina Grande - UFCG, \\ bergnunes22@gmail.com \\ ${ }^{1}$ José Neto de Sousa Santos, Universidade Federal de Campina Grande - UFCG \\ netosousa2303@gmail.com \\ ${ }^{2}$ Henrique Miguel de Lima Silva, Universidade Federal da Paraíba - UFPB, \\ henrique.miguel.91@gmail.com
}

\begin{abstract}
RESUMO
O presente trabalho visa discutir sobre o processo de democratização do ensino no Brasil, bem como sobre as práticas de ensino enquanto instrumentos críticos de diminuição das desigualdades sociais. Partimos do pressuposto de que somente quando o sujeito tem consciência de seu espaço e dos problemas que o circunda podem ser modificados com base na interação social crítica, baseada nos conhecimentos teóricos e na realidade, pode modificar sua história, sendo autor do processo formativo. Baseamos nossa pesquisa em Bourdieu(1982, 1999, 2000, 2005), Freire (1982, 1995, 2000, 2004, 2005), Delamont (2000) dentre outros por abordarem o processo educativo sob o enfoque social crítico. Acreditamos que estes procedimentos contribuem diretamente no entendimento de que o processo formativo deve, por natureza, democratizar oportunidades para todos os envolvidos, sobretudo, para os marginalizados. Dessa maneira, esperamos contribuir para o entendimento da educação enquanto ato político.
\end{abstract}

PALAVRAS-CHAVE: Educação, Democratização, Formação, Autonomia.

\section{DEMOCRATIZATION OF TEACHING: IN SEARCH OF THE DECREASE OF SOCIAL INEQUALITIES}

\begin{abstract}
The present work aims to discuss the process of democratization of education in Brazil, as well as on teaching practices as critical tools for reducing social inequalities. We start from the assumption that only when the subject is aware of its space and the problems that surround it can be modified based on the critical social interaction, based on theoretical knowledge and reality, can modify its history, being the author of the formative process. We base our research on Bourdieu (1982, 1999, 2000, 2005), Freire (1982, 1995, 2000, 2004, 2005), Delamont (2000) among others for addressing the educational process under a critical social approach. We believe that these procedures contribute directly to the understanding that the

Revista de Pesquisa Interdisciplinar, Cajazeiras, n. 2, suplementar, p. 274-283, set. de 2017.
\end{abstract}


training process must, by its nature, democratize opportunities for all those involved, especially those who are marginalized. In this way, we hope to contribute to the understanding of education as a political act.

KEY WORDS: Education, Democratization, Training, Autonomy

\section{DEMOCRATIZACIÓN DE LA ENSEÑANZA: EN BUSCA DE LA DIMENSIÓN DE LAS DESIGUALDADES SOCIALES}

\section{RESUMEN}

El presente trabajo pretende discutir sobre el proceso de democratización de la enseñanza en Brasil, así como sobre las prácticas de enseñanza como instrumentos críticos de disminución de las desigualdades sociales. Partimos del supuesto de que sólo cuando el sujeto tiene conciencia de su espacio y de los problemas que lo circunda pueden ser modificados con base en la interacción social crítica, basada en los conocimientos teóricos y en la realidad, puede modificar su historia, siendo autor del proceso formativo. Basamos nuestra investigación en Bourdieu (1982, 1999, 2000, 2005), Freire (1982, 1995, 2000, 2004, 2005), Delamont (2000) entre otros por abordar el proceso educativo bajo el enfoque social crítico. Creemos que estos procedimientos contribuyen directamente al entendimiento de que el proceso formativo debe, por naturaleza, democratizar oportunidades para todos los involucrados, sobre todo, para los marginados. De esta manera, esperamos contribuir al entendimiento de la educación como acto político.

PALABRAS CLAVE: Educación, Democratización, Formación, Autonomía

\section{INTRODUÇÃO}

O presente trabalho visa discutir sobre o processo de democratização do ensino no Brasil, bem como sobre as práticas de ensino enquanto instrumentos críticos de diminuição das desigualdades sociais.

\footnotetext{
A existência humana é que permite, portanto, denúncia e anúncio, indignação e amor, conflito e consenso, diálogo ou sua negação com a verticalidade de poder. Grandeza ética se antagonizando com as mazelas antiéticas. É exatamente a partir dessas contradições que nascem os sonhos coletivamente sonhados, que temos as possibilidades de superação das condições de vida a que estamos submetidos como simples objetos para tornar-nos todos e todas seres mais (FREIRE, 2001, p.14).
}

Partimos do pressuposto de que somente quando o sujeito tem consciência de seu espaço e dos problemas que o circunda podem ser modificados com base na interação social 
crítica, baseada nos conhecimentos teóricos e na realidade, pode modificar sua história, sendo autor do processo formativo.

Em minha visão "SER" no mundo significa transformar e retificar o mundo, e não adaptar-se a ele. Como ser humano, não resta dúvida de que nossas principais responsabilidades consistem em intervir na realidade e manter nossa esperança (FREIRE, 2001, p. 37).

Baseamos nossa pesquisa em Bourdieu(1982, 1999, 2000, 2005), Freire (1982, 1995, 2000, 2004, 2005), Delamont (2000) dentre outros por abordarem o processo educativo sob o enfoque social crítico.

Em todas as etapas da descodificação, estarão os homens exteriorizando sua visão de mundo, sua forma de pensá-lo, sua percepção fatalista das "situações-limites", sua percepção estática ou dinâmica da realidade. E, nesta forma expressada de pensar o mundo fatalistamente, de pensá-lo dinâmica ou estaticamente, na maneira como realizam seu enfrentamento com o mundo, se encontram envolvidos seus "temas geradores". (FREIRE, 1982, p. 115).

Optamos pela metodologia bibliográfica de estudos, bem como com o enfoque qualitativo, uma vez que objetivos verificar as contribuições de Bourdieu(1982, 1999, 2000, 2005), Freire (1982, 1995, 2000, 2004, 2005), Delamont (2000), dentre outros, para a efetivação do processo democrático nas práticas de ensino e aprendizagem em espaços formais de ensino.

(...) Bourdieu questiona frontalmente a neutralidade da escola e do conhecimento escolar, argumentando que o que essa instituição representa e cobra dos alunos são, basicamente, os gostos, as crenças, as posturas e os valores dos grupos dominantes, dissimuladamente apresentados como cultura universal. (NOGUEIRA \& NOGUEIRA, pág. 03)

Acreditamos que estes procedimentos contribuem diretamente no entendimento de que o processo formativo deve, por natureza, democratizar oportunidades para todos os envolvidos, sobretudo, para os marginalizados. Dessa maneira, esperamos contribuir para o entendimento da educação enquanto ato político. 
(...) os alunos não são indivíduos abstratos que competem em condições relativamente igualitárias na escola, mas atores socialmente constituídos que trazem, em larga medida incorporada, uma bagagem social e cultural diferenciada e mais ou menos rentável no mercado escolar. O grau variado de sucesso alcançado pelos alunos ao longo de seus percursos escolares não poderia ser explicado por seus dons pessoais - relacionados à sua constituição biológica ou psicológica particular -, mas por sua origem social, que os colocaria em condições mais ou menos favoráveis diante das exigências escolares. (NOGUEIRA \& NOGUEIRA, pág. 03)

Obtemos uma percepção de que os alunos inseridos nas escolas são por sua vez provenientes de diferentes realidades sociais, no qual passam por um período de integralização no âmbito escolar, sendo os mesmo submetidos a convivência entre extremos, onde cada um trás consigo uma realidade própria, onde muitas vezes não são comparadas entre as diferenças existentes entre as classes sociais, por sua vez passam a obter o mesmo tratamento fazendo com que não haja uma atenção especial para alunos mais necessitados .

É a partir de este saber fundamental: mudar é difícil, mas é possível, que vamos programar nossa ação político - pedagógica, não importa se o projeto com o qual nos comprometemos é de alfabetização de adultos ou de crianças, se de ação sanitária, se de evangelização, se de formação de mão de - obra técnica (FREIRE, 1996, p. 47).

Dizemos que inserir um padrão de igualdade entre os alunos inseridos no espaço escolar é ir além da realidade que vos é apresentada, desempenhando a necessidade de conhecer melhor a realidade socioambiental e socioeconômica de todos, para que haja um maior desempenho é necessário um comprometimento feito com a educação e não apenas ao alunato, para que possa ocorrer de forma igualitária a vivencia da realidade de cada um, em particular.

(...) O capital econômico (...) e o capital cultural (...) forma de que revestem as diferentes espécies de capital quando percebidas e reconhecidas como legítimas. Assim, os agentes estão distribuídos no espaço social global, na primeira dimensão de acordo com o volume global de capital que eles possuem sob diferentes espécies, e, na segunda dimensão, de acordo com o peso relativo das diferentes espécies de capital, econômico e cultural, no volume total de seu capital. (BOURDIEU, 2004, pág. 154).

(...) As representações dos agentes variam segundo sua posição (...) e segundo seu habitus como sistema de esquemas de percepção e apreciação. 
(...) O habitus é ao mesmo tempo um sistema de esquemas de produção de práticas e um sistema de esquemas de percepção e apreciação das práticas. $\mathrm{E}$, nos dois casos, suas operações exprimem a posição social em que foi construído." (BOURDIEU, 2004, pág. 158).

A escola por sua vez é vista como ambiente de libertação, onde supõe-se que os alunos sentiram-se aptos a desenvolver atividades com maior rendimento, tendo a escola com ambiente conservador de educação, cultura, saberes científicos e cultural, visando ainda um ambiente no qual seria possível visualizar plenamente os mais diversos casos de desigualdade social, uma vez que estarão inseridos alunos provenientes das mais diversas regiões seja da cidade o de regiões circunvizinhas.

É provavelmente por um efeito de inércia cultural que continuamos tomando o sistema escolar como um fator de mobilidade social, segundo a ideologia da "escola libertadora", quando, ao contrário, tudo tende a mostrar que ele é um dos fatores mais eficazes de conservação social, pois fornece a aparência da legitimidade às desigualdades sociais, e sanciona a herança cultural e o dom social tratado como dom natural. (BOURDIEU, 2005, pág. 41).

Visamos a partir de um aporte teórico, compreender a realidade no qual os alunos de diferentes classes sociais estão inseridos, de modo que se tenha um acompanhamento desde as fases iniciais da educação, para que possa ser detectado algo que chegue a comprometer o rendimento dos mesmos, com um provável diagnostico poder encaminhar este aluno para um acompanhamento especializado, tendo como empecilho o questionamento a cerca da equipe responsável por acompanhar o desenvolvimento do aluno na escola desde as fases iniciais, que posteriormente tenderam a seguir uma carreira acadêmica.

Particularmente manifesta nos primeiros anos de escolaridade em que a compreensão e o manejo da língua constituem o alvo de atenção principal no julgamento dos mestres, a influência do capital linguístico não cessa nunca de se exercer: o estilo permanece sempre levado em conta, implícita ou explicitamente, em todos os níveis do ensino médio e, ainda que em graus diversos, em todas as carreiras universitárias, mesmo científicas. (BOURDIEU, 1982, pág. 82).

Embora tenhamos como objetivo principal levantar questões ligadas diretamente as desigualdade social, podemos analisar situações que envolvem fatores sociais aprofundados, quando questionados sobre perspectivas e caráter, interligando a área de estudos, levantando o quão estão preocupados com os objetivos de estudo a ser alcançado, podendo assim promover 
uma expansão no que diz respeito a valores educativos, tendendo a contribuir em analises e utilização de técnicas de desenvolvimento, visando melhorias no processo educacional.

A adopção de perspectivas interacionistas, fenomenológicas ou de inspiração etnográfica, que questionaram a importância anteriormente atribuída a teorias e modelos de carácter geral, se permitiram alargar a compreensão dos fenómenos educativos pela integração de objetos de estudo e níveis de análise até aí raramente utilizados, contribuíram igualmente para um progressivo afastamento da sociologia da educação dos grandes debates sociológicos. Esta situação é assinalada por Sara Delamont ao constatar que a educação passou a estar ausente nos mais recentes desenvolvimentos da teoria sociológica sobre a modernidade tardia, a globalização, a modernidade reflexiva ou a economia dos símbolos e espaço, produzidos entre outros por Beck, Giddens, Lash, ou Urry (Delamont: 2000: 104)

Quando se refere a educação de modo geral é cabível ressaltar fatores externos, que vão além do ato de ensino-aprendizagem, tais fatores devem está voltados as realidades individuais, uma vez que seria necessário uma atenção comum a todos.

Tanto quanto a educação, a investigação que a ela serve, tem de ser uma operação simpática, no sentido etimológico da expressão. Isto é, tem de constituir-se na comunicação, no sentir comum uma realidade que não pode ser vista mecanicistamente compartimentada, simplistamente bem "comportada", mas, na complexidade de seu permanente via a ser. (FREIRE, 1982, p. 118).

Podemos observar inúmeros casos ocorrentes nas ruas, algumas vezes em ambientes fora da escola, nestes casos ocorrem situações que podem ser evitados quando se há um dialogo especializado, voltado a cada situação. Tendo como base a educação que cada vez concretiza-se com ações de evolução ligadas diretamente a outras ações sociais, que vão além do ambiente escolar, gerando uma associação interdisciplinar.

Tanto quanto a educação, a investigação que a ela serve, tem de ser uma operação simpática, no sentido etimológico da expressão. Isto é, tem de constituir-se na comunicação, no sentir comum uma realidade que não pode ser vista mecanicistamente compartimentada, simplistamente bem "comportada", mas, na complexidade de seu permanente via a ser. (FREIRE, 1982, p. 118)

$\mathrm{O}$ investigador da temática significativa que, em nome da objetividade científica, transforma o orgânico em inorgânico, o que está sendo no que é, o vivo no morto, teme a mudança. Teme a transformação. Vê nesta, que não nega, mas que não quer, não um anúncio de vida, mas um anúncio de morte, de deterioração. Quer conhecer a mudança, não para estimulá-la, para aprofundá-la, mas para freiá-la. (FREIRE, 1982, p. 118). 
Quando obtemos um resultado que implique em casos de desigualdade social explicita, podemos buscar maneiras de auxiliar no processo democrático de educação, utilizando de termos simples que possam expressar com clareza, situações delicados, por sua vez subtendese que o diagnostico a cerca da diferença existente entre classes sociais presentes no ambiente escolar deve acontecer desde o momento que o aluno ingresse na escola, sem agir como agentes passivos, que visam o surgimento do problema em estagio avançado para em seguida buscar soluções cabíveis.

$\mathrm{Na}$ medida em que representam situações existenciais, as codificações devem ser simples na sua complexidade e oferecer possibilidades plurais de análises na sua descodificação, o que evita o dirigismo massificador da codificação propagandística. As codificações não são slogans, são objetos cognoscíveis, desafios sobre que deve incidir a reflexão crítica dos sujeitos descodificadores. As codificações, de um lado, são as mediação entre o "contexto concreto ou real", em que se dão os fatores e o "contexto teórico", em que são analisadas; de outro, são o objeto cognoscível sobre que o educador-educando e os educando-educadores, como sujeitos cognoscentes, incidem sua reflexão crítica. (FREIRE, 1982, p. 128).

Somente um ser que é capaz de sair de seu contexto, de "distanciar-se" dele para ficar com ele; capaz de admirá-lo para, objetivando-o, transformá-lo e, transformando-o, saber-se transformado pela sua própria criação; um ser que está sendo no tempo que é o seu, um ser histórico, somente este é capaz, por tudo isto, de comprometer-se (FREIRE, 1983, p.17).

O papel fundamental do professor é ensinar, embora mediante as situações presentes na atualidade, cabe ao mesmo identificar casos especiais em sala de aula, para que haja uma democratização é essencial que todos estejam no mesmo nível, porem a realidade é relevantemente diferente, já que é possível aprender coisas a cada dia, em muitos caos esse aprendizado é proveniente da interação entre aluno e professor, estabelecendo uma relação de participação condizente em sala de aula.

O educador já não é mais o que educa, mas o que, enquanto educa, é educado, em diálogo com o educando que, ao ser educado, também educa. Ambos, assim, se tornam sujeitos do processo em que crescem juntos (FREIRE, 2005, p.79).

Enquanto para um professor elitista, por exemplo, a Educação em Direitos Humanos tem a ver com o tratamento fidalgo do conhecimento, isto é, tratar o ato de conhecer fidalgamente, para um professor progressista a discussão sobre o ato de conhecer se apresenta como um direito dos homens e mulheres das classes populares, que vêm sendo proibidos e proibidas de 
exercer este direito, o direito de conhecer melhor o que já conhecem, porque praticam, e o direito de participar da produção de conhecimento que ainda não existe (FREIRE, 2001, p. 97).

A educação quando trabalhada de forma adequada, seguida do cumprimento de normas elencares para bom funcionamento e desempenho da equipe escolar, proporciona uma relação de interesse entre as partes evolvidas no processo de ensino-aprendizagem, quando se tem uma aula onde todos podem expressar sua opinião, sendo ouvidos de forma respeitosa, contribuindo para o desempenho da aula.

Por isso é que a educação ligada aos direitos humanos, nesta perspectiva que passa pela compreensão das classes sociais, tem que ver com educação e libertação e não com liberdade apenas. Tem a ver com libertação precisamente porque não há liberdade; e a libertação é exatamente a briga para restaurar ou instaurar a gostosura de ser livre que nunca finda, que nunca termina e sempre começa (FREIRE, 2001, p. 100).

Portanto a perspectiva da Educação em Direitos Humanos que defendemos, é esta, de uma sociedade menos injusta para, aos poucos, ficar mais justa. Uma sociedade reinventando-se sempre com uma nova compreensão do poder, passando para uma nova compreensão da produção. Uma sociedade em que a gente tenha gosto de viver, de sonhar, de namorar, de amar, de querer bem. Esta tem que ser uma educação corajosa, curiosa, despertadora, da curiosidade, mantenedora da curiosidade, por isso mesmo uma educação que, tanto quanto possível, vai preservando a menina que você foi sem deixar que a maturidade a mate (FREIRE, 2001, p. 101).

Subtendemos que ações sociais podem gerar momentos produtivos e pertinentes, possibilitando uma base de qualidade para os estudos futuros, com isso proporciona um desempenho de ambas as partes envolvidas no processo de educação, de tal forma, contribuindo no âmbito social, gerando um desenvolvimento adequado de atividade sociocultural e socioambiental, favorecendo em uma democratização no ensino gerando uma estabilidade social reduzindo a desigualdade social.

Essa Educação para a liberdade, essa educação ligada aos direitos humanos nesta perspectiva, tem que ser abrangente totalizante; ela tem que ver com o conhecimento crítico do real e com a alegria de viver. E não apenas com a rigorosidade da análise de como a sociedade se move, se mexe, caminha, mas ela tem a ver também com a festa que é a vida mesma. Mas é preciso fazer isso de forma crítica e não de forma ingênua. Nem aceitar o todo poderosismo ingênuo de uma educação que faz tudo, nem aceitar a negação da educação como algo que nada faz, mas assumir a educação nas suas 
limitações e, portanto, fazer o que é possível, historicamente, ser feito com e através, também, da educação (FREIRE, 2001, p. 102).

\section{CONSIDERAÇÕES FINAIS}

É significativa e necessária uma análise crítica e reflexiva quanto às práticas educacionais observadas e quanto à escola como colaboradora no processo de ensinoaprendizagem, tendo em vista a mesma como um ambiente com condições propicia para o acolhimento dos mais diversos públicos, onde a mesma deve oferecer um nível educacional equivalente a todos.

Vale ainda ressaltar que a escola não pode se restringir, apenas a pratica de ensinar, mas também oferecer o acompanhamento aos que ali estão inseridos, oferecendo um acompanhamento especializado, mesmo que a distancia às vezes, desde as fases iniciais da educação, para que possam ser diagnosticadas situações que tendem a prejudicar o rendimento escolar e social dos que ali estão inseridos, com um provável diagnostico podemos encaminhar este aluno para um acompanhamento especializado. Com o apoio familiar, social, e de toda equipe escolar, onde muitas vezes são questionados de seu nível de formação e comprometimento com o trabalho.

Logo, somente quando o sujeito tem consciência de seu espaço e dos problemas que o circunda podem ser modificados com base na interação social crítica, baseada nos conhecimentos teóricos e na realidade, podendo modificar sua própria história. 


\section{REFERÊNCIAS}

BOURDIEU, P. A reprodução: Elementos para uma teoria do sistema de ensino. Rio de Janeiro: Ed. Francisco Alves, 1982.

BOURDIEU, P. Escritos de Educação. Petrópolis, RJ: Ed. Vozes, 2005.

BOURDIEU, P. A ruptura. A profissão do sociólogo. Petrópolis, RJ: Ed. Vozes, 1999.

BOURDIEU, P. Espaço social e poder simbólico. Coisas Ditas. São Paulo: Brasiliense, 2004.

DELAMONT, Sara (2000), "The Anomalous Beasts: Hooligans and the Sociology of Education", Sociology, 34(1), pp. 95-111.

FREIRE, P. Pedagogia da autonomia. São Paulo: Paz e Terra, 2006.

FREIRE, Paulo. A importância do ato de ler: em três artigos que se completam. 26 ed. São Paulo: Cortez, 1991.

.̀̀ sombra desta mangueira. 2.. ed. São Paulo: Olho d'Água, 1995. 120 p. Educação como prática da liberdade. 25. ed. São Paulo: Paz e Terra, 2001.158 p.

Pedagogia da autonomia: saberes necessários à prática educativa. 30 . ed. Rio de Janeiro: Paz e Terra, 2004. 148 p. (Coleção leitura )

Pedagogia da esperança: um reencontro com a pedagogia do oprimido.

7. ed. Rio de Janeiro: Paz e Terra, 2000. 245 p.

Pedagogia do oprimido. 11. ed. Rio de Janeiro: Paz e Terra, 1982. F

REIRE'S AND ILLICH'S. Conscientization and Deschooling. Philadelphia: The Westminster Pres, 1976.

FREIRE, Paulo \& ILLICH, Ivan. Dialogo: análisis crítico de la "desescolarización" y "concientización" en la coyuntura actual del sistema educativo. Buenos Aires: Ediciones Busqueda, 1975.

NOGUEIRA, C. M. M. N., NOGUEIRA, M. A. A sociologia da educação de Pierre Bourdieu: limites e contribuições,. Educ. Soc. v.23 n.78 Campinas abr. 2002 